\title{
BIOSSEGURANÇA NO CENTRO DE MATERIAIS E ESTERILIZAÇÃO: DÚVIDAS DOS PROFISSIONAIS*
}

\author{
Biosecurity in Central Sterile Services Department: the doubts of professionals \\ Bioseguridad en el Centro de Materiales y Esterilización: dudas de los profesionales \\ Solinei Paulo Borgheti', Karin Viegas², Rita Catalina Aquino Caregnato $^{3}$
}

RESUMO: Objetivos: Conhecer as dúvidas dos profissionais da saúde sobre biossegurança no Centro de Materiais e Esterilização (CME) e refletir sobre as respostas emitidas. Método: Estudo exploratório descritivo qualitativo. O cenário da pesquisa foi um site nacional reconhecido que dispõe uma lista de discussão por e-mail. O corpus foram 2.260 mensagens enviadas à lista de discussão em 2014; a amostra foi composta por 109 mensagens com conteúdo relacionado à biossegurança no CME. Utilizou-se para interpretação dos dados a Análise de Conteúdo de Bardin. Resultados: Na análise emergiram quatro categorias temáticas das dúvidas mais frequentes denominadas: soluções; equipamentos e materiais; Legislação; e validação do processo. Evidenciou-se forte relação entre CME e Controle de Infecção Hospitalar (CIH), tanto nos questionamentos quanto nas respostas. Conclusão: A maioria dos profissionais que encaminharam dúvidas foram enfermeiros. As dúvidas mais frequentes sobre biossegurança relacionavam-se a soluções usadas, equipamentos e materiais. As respostas foram fundamentadas na legislação vigente e emitidas por profissionais com experiência.

Palavras-chave: Segurança de equipamentos médicos. Enfermagem. Material.

ABSTRACT: Objective: This work aims at knowing the doubts health professionals may have about biosecurity in Central Sterile Services Department (CSSD), and reflect upon the answers. Methods: This is a qualitative, descriptive exploratory study. The research was about a well known Brazilian website, which offers a discussion list by e-mail. 2,260 messages were sent to this list in 2014. The sample was composed by 109 messages containing topics about biosecurity in CSSD; interpreted using the Bardin's Content Analysis. Results: Four theme categories emerged from the most frequent questions: chemical solutions, equipment and materials, Law, and process validation. Both in questions as in answers analyzed, there was a strong relation between the CSSD and Hospital Infection Control. Conclusions: Most professionals who referred questions were nurses. The most frequently asked questions on biosecurity related to the solutions used, equipment and materials. The answers were based on existing legislation and issued by professionals with experience. Keywords: Equipment safety. Nursing. Materials.

RESUMEN: Objetivos: Conocer las dudas de profesionales de la salud sobre bioseguridad en el Centro de Materiales y Esterilización (CME) y reflexionar sobre las respuestas fornecidas. Método: Estudio exploratorio descriptivo cualitativo. El escenario de la investigación fue un sitio electrónico reconocido que dispone de una lista de discusión por correo electrónico. 2.260 mensajes fueron enviados a la lista de discusión en 2014; la muestra se compuso de 109 mensajes con contenido relacionado a la bioseguridad en el CME. El análisis de contenido de Bardin fue empleado para la interpretación de los datos. Resultados: Emergieron en el análisis cuatro categorías temáticas de las dudas más frecuentes, denominadas: soluciones; equipamientos y materiales; legislación y validación del proceso. Se evidenció una fuerte relación entre el CME y el Control de Infección Hospitalaria, en tanto en los cuestionamientos y en las respuestas. Conclusión: La mayoría de los profesionales que refirieron las preguntas eran enfermeros. Las preguntas más frecuentes sobre bioseguridad eran relacionadas a las soluciones utilizadas, a los equipos y los materiales. Las respuestas se basaron en la legislación vigente y fueron emitidas por profesionales peritos. Palabras clave: Seguridad de equipos. Enfermería. Material.

\footnotetext{
*Artigo produzido a partir do Trabalho de Conclusão do Curso de Enfermagem da Universidade Federal de Ciências da Saúde de Porto Alegre (UFCSPA) em 2015. 'Enfermeiro graduado pelo Curso de Enfermagem da UFCSPA - Porto Alegre (RS), Brasil.

¿Doutora em Gerontologia Biomédica; Professora do Curso de Graduação em Enfermagem da UFCSPA - Porto Alegre (RS), Brasil.

${ }^{3}$ Doutora em Educação; Professora do Curso de Graduação em Enfermagem da UFCSPA - Porto Alegre (RS), Brasil. E-mail: ritac.ufcspa@gmail.com

Rua Dr Rodrigues Alves, 273, apto. 203 - Chácara das Pedras - CEP: $91330-240$ - Porto Alegre (RS), Brasil.

Recebido: 29 nov. 2015 - Aprovado: 22 fev. 2016

DOI: $10.5327 / 21414-4425201600010002$
} 


\section{INTRODUÇÃ̃o}

A biossegurança constitui-se em um desafio para os profissionais da saúde, principalmente no campo prático de um setor pouco conhecido como o Centro de Materiais e Esterilização (CME). Esse setor de apoio tem fundamental importância por ser responsável pelo processamento de produtos para saúde (PPS), garantindo segurança ao paciente e permitindo o uso de materiais em condições adequadas de preparo e esterilização ${ }^{1}$.

No hospital, o CME é considerado uma área crítica por processar artigos resultantes de intervenções clínicas e cirúrgicas, apresentando, desta forma, riscos aos profissionais que atuam nesse setor, tornando-os mais suscetíveis a acidentes ocupacionais $^{2}$.

A biossegurança pode ser enfocada em duas direções: tanto em relação aos organismos geneticamente modificados e seus derivados quanto às atividades inerentes a biotecnologia, proteção social e ocupacional dos trabalhadores. Esta pesquisa enfoca a última citada, uma vez que entre seus objetivos está a preservação da saúde dos profissionais, da coletividade, do ambiente e também devido às questões éticas e legais, visto que um descuido pode tornar-se uma ameaça ${ }^{3}$, gerando processos jurídicos.

A Norma Regulamentadora ${ }^{\circ} 32$ (NR-32) trata da segurança e saúde no trabalho em serviços de saúde, sendo considerada um grande avanço para os trabalhadores dessa área, pois estabelece diretrizes para a implementação de medidas de proteção à saúde e segurança do trabalhador ${ }^{4}$. Para implantar a NR-32 nos serviços são necessários investimentos em recursos físicos, materiais e pessoais, além de capacitação e motivação dos funcionários e administradores, criando novos conceitos culturais e comportamentais ${ }^{4,5}$.

A fim de normatizar todo o trabalho e garantir a segurança dos artigos processados no CME, a Agência Nacional de Vigilância Sanitária (Anvisa) publicou, em 2012, a Resolução n ${ }^{\circ} 15$ (RCD-15), sobre os requisitos de boas práticas para o processamento de produtos para saúde, sendo um marco histórico importante por tratar, entre outras seções, dos recursos humanos, da segurança e saúde no trabalho e das atribuições do responsável técnico ${ }^{6}$. Embora a RDC-15 não especifique a formação profissional do responsável por esse setor (apenas cita que deverá ter nível superior), acredita-se que o enfermeiro seja o profissional mais indicado para ocupar esse cargo, pois sua formação lhe confere competências técnica e gerencial para administrar esse setor, além de ter conhecimento aprofundado sobre o cuidado integral do paciente ${ }^{6}$. Entretanto, percebe-se que a enfermagem vem perdendo o interesse em atuar nessa área, abrindo espaço para a atuação de outros profissionais da saúde ou da área administrativa com interesse nesse setor.

O trabalho não bem executado no CME poderá acarretar risco para a saúde de trabalhadores e pacientes, uma vez que esse setor se articula com todas as unidades hospitalares, fornecendo artigos para prestação de serviços, criando uma relação de interdependência, na qual a qualidade dos serviços realizados está diretamente ligada à qualidade e à segurança dos produtos processados no $\mathrm{CME}^{7}$.

Sabe-se que falhas no CME podem ocorrer por desatualização dos profissionais; falta de padronização das ações; não adesão ao uso de Equipamentos de Proteção Individual (EPIs); e execução de técnicas inadequadas ${ }^{8}$.

O trabalho no CME poderá ser comprometido por vários fatores, tais como: infraestrutura inadequada; dinâmica das relações humanas; falta de qualificação dos profissionais; pressões do serviço; e exigência de produtividade 9 Portanto, inúmeros fatores podem estar relacionados aos acidentes ocorridos nesse setor, como: sobrecarga de trabalho; jornadas fatigantes; desgaste físico; plantões noturnos; falta de atenção; excesso de confiança; falta de condições; falta de capacidade técnica; entre outros. Os maiores riscos à exposição dos profissionais de saúde ocorrem nos locais de trabalho insatisfatório, desorganização dos serviços, deficiência de recursos humanos e materiais e área física inadequada do ponto de vista ergonômico ${ }^{10}$.

Para garantir eficiência e segurança nos processos de trabalho, tornam-se necessárias a constante atualização e a existência de uma postura comprometida dos profissionais que exercem suas atividades laborais ${ }^{9}$. A adoção de medidas de biossegurança é prioritária para todos os setores e profissionais da saúde expostos aos riscos ocupacionais, sendo a educação fundamental; entretanto, os temas biossegurança e CME são pouco discutidos na formação dos profissionais de enfermagem ${ }^{1}$.

Durante a graduação do curso de enfermagem aprendeuse a importância da biossegurança para garantir um cuidado de forma segura, tanto para o paciente quanto para o profissional, tendo a oportunidade de aprender a teoria e ter vivência prática no CME. Ao saber que muitos cursos de graduação em enfermagem não abordam conteúdo teórico-prático sobre essa área, surgiu como interesse pesquisar sobre as dúvidas dos profissionais da saúde sobre biossegurança no CME. 
A inquietação e a busca de conhecimentos conduziram a descoberta de um site reconhecido nacionalmente que debate as dúvidas dos profissionais da saúde sobre essa temática. Neste contexto, surgiu o interesse em investigar o problema de pesquisa: quais são as dúvidas mais frequentes sobre biossegurança no CME e como são debatidas e esclarecidas no site? Para atender ao problema traçado, definiram-se como objetivos desta pesquisa: conhecer as dúvidas dos profissionais da saúde sobre biossegurança no CME e refletir sobre as respostas emitidas.

\section{MÉTODO}

Trata-se de um estudo exploratório descritivo com abordagem qualitativa.

A fim de esclarecer as dúvidas frequentes dos profissionais da área da saúde, existe um site nacional sobre risco biológico que tem como missão prevenir riscos biológicos ocupacionais para os seus trabalhadores. Dentro desse ambiente virtual existe um espaço de discussão via e-mail. Esse site (http: / / www.riscobiologico.org/) tem como finalidade divulgar informações sobre riscos biológicos aos profissionais da saúde por meio de ações de ensino, pesquisa, vigilância e intercâmbio, divulgando informações atualizadas e auxiliando nos aspectos técnicos de questões relacionadas aos riscos biológicos para trabalhadores da saúde.

Considerou-se o corpus para esta pesquisa todas as mensagens de e-mail enviadas para o grupo de discussão do site de janeiro a dezembro de 2014, totalizando 2.260 mensagens. A amostra constituiu-se de 109 mensagens que atenderam aos seguintes critérios de inclusão: terem sido enviadas ao grupo de discussão no ano 2014 e apresentarem em seu conteúdo dúvidas relacionadas ao CME.

Para a coleta dos dados inicialmente o pesquisador realizou o cadastro no site em 2012, após conhecimento deste por indicação da orientadora. No mesmo ano realizou sua inscrição na lista de discussão, a fim de ter acesso a ela. Todos os e-mails recebidos foram salvos e armazenados em arquivo próprio, iniciando em janeiro e finalizando em dezembro de 2014. Os e-mails tinham as dúvidas iniciais e as respostas discutidas pelo grupo de discussão.

O pesquisador realizou a leitura dos e-mails e, ao identificar o tema sobre CME, salvou a mensagem em arquivo próprio. Após, criou uma planilha em Excel ${ }^{\circledR}$ contendo quantitativo das dúvidas, profissões que encaminhavam dúvidas e respostas apresentadas.
Realizou-se Análise de Conteúdo temática de Bardin ${ }^{11}$, seguindo as etapas de:

1. pré-análise: organização do material, leitura breve dos e-mails e identificação das repetições e sistematização das ideias para a análise;

2. descrição analítica: categorização dos dados por meio do critério temático, agrupando-se os temas semelhantes com o mesmo significado; e

3 interpretação inferencial: dados foram interpretados realizando-se inferências, objetivando tornar válidos e significativos os resultados.

A análise foi realizada por meio da leitura na íntegra de todas as mensagens selecionadas e agrupadas inicialmente por título da mensagem encaminhada, chegando-se, assim, ao total de 19, criando-se pré-categorias relacionadas às repetições do conteúdo das dúvidas. Após realizar novamente a leitura na íntegra do conteúdo, destacaram-se as unidades de registros (UR) repetitivas, agrupando-se pela semelhança das dúvidas e respostas, emergindo as categorias finais e subcategorias. Seguindo, realizou-se a contagem das UR, expressas em número inteiro, calculando o percentual.

$\mathrm{Na}$ análise, os profissionais que enviaram suas dúvidas ao site foram identificados pelas letras iniciais da sua formação profissional, seguidas de um número para diferenciar os sujeitos. Acrescentar números às letras codificadas por profissões foi necessário devido ao quantitativo de profissionais da mesma categoria. Aos e-mails sem identificação profissional convencionou-se usar a abreviatura NI (não identificado). A pesquisa foi submetida ao Comitê de Ética e Pesquisa (CEP) da Universidade, sendo aprovada sob parecer número 93.4017. Após aprovação, entrou-se em contato com o responsável técnico pelo site, o qual autorizou a pesquisa após receber o projeto e parecer aprovado.

\section{RESULTADOS}

Identificaram-se nos e-mails os seguintes profissionais de nível superior: 30 enfermeiros (E), 5 médicos $(M), 5$ engenheiros clínicos (EC), 5 farmacêuticos (F), 2 veterinários (V), 1 engenheiro de segurança trabalho (EST). Além desses, também foram identificados profissionais de nível técnico: três técnicos de segurança do trabalho (TST) e dois técnicos em higienização hospitalar (THH). Profissionais não identificados (NI) totalizaram 19. 
O Quadro 1 apresenta as quatro categorias finais, subcategorias emergidas, UR e percentuais das principais dúvidas enviadas para a lista de discussão.

Evidenciou-se uma relação existente forte entre CME e o Controle de Infecção Hospitalar (CIH), tanto nos questionamentos quanto nas respostas.

\section{Soluções}

Nesta categoria emergiram três subcategorias: nomes comerciais; concentrações, diluições e validade; e custos. Na subcategoria "nomes comerciais", os profissionais expressaram suas dúvidas a respeito de quais produtos são mais adequados para realizar desinfecção química tanto de baixo quanto de alto nível, dos mais variados materiais utilizados na área hospitalar, tais como: nebulizadores, umidificadores, ambus,

Quadro 1. Categorias, subcategorias e quantidade de unidades de registros, com percentuais correspondentes, emergidas das dúvidas dos profissionais da saúde sobre Centro de Materiais e Esterilização no site de discussão, de janeiro a dezembro de 2014.

\begin{tabular}{|c|c|c|c|}
\hline Categorias & Subcategorias & UR & $\%$ \\
\hline \multirow{4}{*}{ Soluções } & Nomes comerciais & 124 & 72,90 \\
\hline & $\begin{array}{c}\text { Concentrações, diluições e } \\
\text { validade }\end{array}$ & 34 & 20,00 \\
\hline & Custos & 12 & 7,05 \\
\hline & Total de unidades de registros & 170 & 100 \\
\hline \multirow{7}{*}{$\begin{array}{l}\text { Equipamentos } \\
\text { e materiais }\end{array}$} & $\begin{array}{l}\text { Métodos de esterilização/ } \\
\text { desinfecção }\end{array}$ & 69 & 40,5 \\
\hline & Instrumentos & 59 & 34,7 \\
\hline & Reprocessamento & 12 & 7,0 \\
\hline & Embalagens & 11 & 6,4 \\
\hline & Biofilme & 10 & 5,8 \\
\hline & $\begin{array}{l}\text { Manutenção (vida útil, dano, } \\
\text { preservação, conservação) }\end{array}$ & 10 & 5,8 \\
\hline & Total de unidades de registros & 171 & 100 \\
\hline \multirow{4}{*}{ Legislação } & Normas/Portarias & 56 & 50,9 \\
\hline & Lei/Legal & 37 & 33,6 \\
\hline & Anvisa & 17 & 15,5 \\
\hline & Total de unidades de registros & 110 & 100 \\
\hline \multirow{3}{*}{$\begin{array}{l}\text { Validação do } \\
\text { processo }\end{array}$} & Tempo & 39 & 54,9 \\
\hline & Testes & 32 & 45,1 \\
\hline & Total de unidades de registros & 71 & 100 \\
\hline
\end{tabular}

UR:unidades de regsitros. extensores de oxigênio, aparelhos utilizados para endoscopia e instrumentais cirúrgicos, conforme expresso na UR a seguir:

Gostaria de saber o que está sendo usado para a desinfecção de endoscópio [referiu-se ao nome comercial do glutaraldeído] ou ácido paracético? (NI1).

Alguém tem alguma informação baseado em legislação sobre a desinfecção de alto nível do ácido peracético em 10 minutos? Alguém utiliza ou conhece o [...]? (E11).

Em relação às dúvidas, um farmacêutico respondeu:

Os produtos seguem uma legislação. No caso referido, para desinfetantes, é a RDC 35/10, onde especifica os laudos microbiológicos exigidos para registro, em que o tempo máximo de imersão é o do microrganismo que leva mais tempo para ser eliminado. (F1).

Na subcategoria "concentrações, diluições e validade", a principal dúvida encontrada foi sobre a forma correta de diluir várias soluções existentes, mantendo a concentração adequada para garantir processos de limpeza, desinfecção e esterilização seguros, sem causar danos aos usuários, conforme UR a seguir:

Quais são atualmente as concentrações x necessidade de enxágue para o hipoclorito de sódio das máscaras utilizadas para nebulização/ambu [...]? (NI14).

Tenho lido sobre desinfecção [referindo-se ao hipoclorito] [...], mas existem controvérsias referentes a diluição e concentração para tal prática. Gostaria de saber o que é preconizado pela Anvisa: 0,02\%, $1 \%, 0,5 \%$ ? (E26).

Como resposta aos questionamentos sobre o hipoclorito, um enfermeiro respondeu:

Exceto para artigos utilizados em casos de tuberculose pulmonar ativa, recomendo hipoclorito a $0,02 \%$ por 30 minutos. A solução deverá ser trocada todos os dias. (E27).

Na subcategoria "custos”, apareceram dúvidas em relação a soluções mais caras; formas de reduzir os custos 
de aquisição das soluções; como utilizar as soluções de maneira segura sem causar aumento de custos para as instituições, por danos e mau uso; e forma correta de armazenamento.

Estou tendo dificuldade em padronizar a compra do hipoclorito no almoxarifado [...], mas o almoxarifado tá reclamando que custa caro, comprar um com uma concentração maior e depois diluir sugeriu. (NI16).

As respostas tentam esclarecer e passam recomendações, como esta:

[...] substitua por ácido peracético $5 \%$, o custo será menor e a qualidade da desinfecção melhor (NI17).

E todo esse processo fica mais barato que o descarte? (EC5).

Recomendo utilizar ácido peracético. [...]. A solução pode ser utilizada por vários dias, perfeitamente monitorada, e, se a questão é custo, você vai se surpreender. Você tem várias opções e preços no mercado, pó, líquidos, pronto-uso, concentrados, com ou sem inibidores de corrosão [… (EC2).

Também nesta subcategoria se discute o melhor preço para aquisição de equipamentos, como lavadoras ultrassônicas e autoclaves mais modernas, como alternativas para substituir as soluções como sugere.

\section{Equipamentos e materiais}

Na categoria "equipamentos e materiais", surgiram seis subcategorias denominadas: métodos de esterilização/ desinfecção; instrumentos; reprocessamento; embalagens; biofilme; e manutenção. Sobre métodos de esterilização/desinfecção, as dúvidas foram relacionadas a qual o método utilizado para realizar esse processo ou qual solução é empregada e qual escolha tem melhor eficácia, como aparece no recorte:

Qual material vocês utilizam para desinfecção dos materiais respiratórios [...]? (E25).
Outra enfermeira respondeu:

Exceto para artigos utilizados em casos de tuberculose pulmonar ativa, recomendo hipoclorito a $0,02 \%$ por 30 minutos. A solução deverá ser trocada todos os dias. (E27).

Surgiu uma questão específica sobre a desinfecção do endoscópio:

Gostaria de saber o que está sendo usado para desinfecção de endoscópio [...]? (NI10).

Englobando também outras dúvidas que apareceram em relação a esse tipo de equipamento, seguiu-se a seguinte resposta:

[...] nós, controladores de infecção hospitalar, recomendamos que seja utilizado para desinfecção de endoscópio o ácido peracético, porém, esse produto diminui a vida útil de alguns aparelhos, principalmente quando não se é retirada a película formada em sua lente que anteriormente recebia ação do glutaraldeído. Existe, atualmente, no mercado, ácido peracético com $\mathrm{pH}$ mais alcalino, o que favorece a conservação dos aparelhos. Quanto ao [...] [nome comercial citado], é também um excelente produto que não compromete a vida útil do aparelho, porém possui um custo mais elevado e necessita que seja inativado para descarte. (NI8).

Ao discutirem esse tópico, os profissionais apresentaram mais de uma forma de métodos de desinfecção/esterilização que podem ser usados para o mesmo material, dependendo de vários fatores para sua escolha, como a instituição, a modernidade dos equipamentos usados no CME, a indicação do fabricante e o que é preconizado pelo $\mathrm{CIH}$, como aparece no recorte a seguir:

Alguém sabe com que produto faço a desinfecção de termômetro esofágico $[\ldots]$ ?.

A resposta foi:

Desinfecção química de alto nível, já que o termômetro esofágico é sensível a altas temperaturas e não suportaria a desinfecção térmica. (F2). 
Na subcategoria "instrumentos", as dúvidas identificadas foram em relação à marcação de instrumentais cirúrgicos tais como pinças, furadeiras pneumáticas, bandejas, pinças e outros, além do possível surgimento de biofilme ao se utilizar alguns tipos de materiais para realizar essa marcação, como aparece no recorte:

[...] existe legislação referente a marcação de material cirúrgico? (E8).

Discute-se a utilização de fitas para marcação dos instrumentais, mas novamente surge a questão do biofilme:

$\mathrm{O}$ vapor realmente não penetra a camada de fita com adesivo e ela ainda mancha o instrumental e, com o ressecamento do adesivo, com certeza formam biofilme. Não há nada definitivo em relação à marcação de instrumentais a não ser a marcação a laser. (NI7).

Na subcategoria "reprocessamento", discute-se sobre o reprocessamento de alguns materiais que deveriam ser de uso único; no entanto, pelos mais diversos motivos, algumas vezes acabam sendo reprocessados seguindo uma série de regras.

Tenho uma dúvida com relação ao reprocessamento de um material. (E28).

Se o fabricante diz que o produto é de uso único, ele não deve ser reprocessado. (E29).

Na subcategoria "embalagens", as dúvidas foram voltadas para qual tipo de material é o mais seguro para embalar caixas e outros instrumentais cirúrgicos que irão passar pelo processo de esterilização, ou qual o melhor tipo de embalagem para artigos que vão sofrer apenas o processo de desinfecção. As dúvidas estavam associadas a qual tipo de embalagem é mais adequado para cada material, levando-se em consideração os custos de cada uma, associado à segurança do processo em questão e às normas que envolvem esses processos.

Estou iniciando as atividades num centro cirúrgico e neste há adoção de papel crepado para embalagem de caixas cirúrgicas. Gostaria de saber se há alguma norma que proíbe o uso deste insumo [...]. (E1).
Ainda não há normas que proíbam esse tipo de sistema de barreira estéril, mas o papel deve apresentar especificações técnicas apropriadas e ter registro na Anvisa. (N1).

Na subcategoria denominada "manutenção", aparecem questionamentos sobre vida útil do equipamento/material; danos; preservação e conservação; soluções utilizadas para fazer limpeza, desinfecção e esterilização; e substituição de algum produto por outro, mantendo a conservação e prolongando a vida útil dos equipamentos garantindo segurança para quem vai utilizar esses produtos.

[...] os instrumentais de laparoscopia todos devem ser esterilizados, mas aqui na minha instituição nem todos materiais de cirurgias por vídeo podem ser autoclavados. Como é feito nos outros hospitais? (E11).

Essa pergunta ficou sem resposta, pois são discutidas nas respostas a troca dos métodos de desinfecção e esterilização e a troca de equipamento (termorresistentes) mais modernos.

[...] a troca do método de desinfecção do glutaraldeído para o ácido peracético pode danificar os equipamentos [...] Alto risco de perda dos equipamentos. (M2).

\section{Legislação}

Nesta categoria, surgiram três subcategorias, denominadas: "Normas/Portarias"; "Lei/ Legal" e "Anvisa". Na subcategoria "Normas/Portarias", os profissionais expressaram suas dúvidas em relação a em qual norma ou portaria deveriam se basear para a tomada de decisão a respeito do produto a ser utilizado ou como utilizar e, concomitantemente, surgiram também dúvidas sobre os aspectos legais e as leis que regulamentam o uso de produtos, embalagens, substâncias e equipamentos, fazendo com que essas subcategorias apareçam em vários momentos.

Alguém tem alguma informação baseado em legislação sobre a desinfecção de alto nível do ácido peracético? (E11).

A Legislação vigente para registro de Desinfetante de Alto nível (Peracético) é a RDC 33/2010. (EC4). 
Na subcategoria "Anvisa", as principais dúvidas foram voltadas para o reprocessamento de materiais e sobre quais materiais estão presentes na lista que não devem ser reprocessados.

Eu tinha essa dúvida, porém com ajuda a consegui definir. Pois precisa verificar como o fabricante registrou o produto na Anvisa, o produto que utilizo da marca [...] tem o registro como de uso único, portanto as Cânulas de Guedel não são reutilizáveis. (E23).

\section{Validação do processo}

Na categoria "validação do processo", surgiram duas subcategorias: "tempo" e "testes".

A subcategoria "tempo" está relacionada às dúvidas dos profissionais em relação ao tempo que deve ficar imerso um produto para que a limpeza ou desinfecção ocorra de forma eficiente e segura.

[...] desinfecção de alto nível do ácido peracético em 10 minutos? (E11).

Conforme metodologia do INCQS utilizada para ensaio de eficácia micobactericida o tempo de contato é de no mínimo 30 minutos. (F1).

Na subcategoria "testes", as principais dúvidas foram em relação aos testes que devem ser realizados para validar as cargas de esterilização das autoclaves, qual a quantidade destes que deve ser usado em cada carga, qual melhor localização com a finalidade de garantir um processo de esterilização seguro.

[....] Quatro ampolas ou pode ser utilizada somente uma dentro da autoclave e a outra como controle? (E20).

O que é indicador biológico? (EC1).

Como resposta aparece:

A RDC 15, de 15 de março de 2014, da Anvisa, está muito boa, ela explica sobre os testes que você deve utilizar e a frequência. (E21).

\section{DISCUSSÃO}

Na categoria denominada "soluções", muitas dúvidas eram referentes aos nomes comerciais das soluções utilizadas em todas as etapas do processo de preparo do material (limpeza, desinfecção ou esterilização). Os profissionais queriam saber qual era a solução mais eficaz, segura e de menor custo para ser usada na instituição.

Um estudo ${ }^{12}$ aponta a dificuldade encontrada pelos profissionais em fazer a escolha de soluções enzimáticas para a limpeza dos materiais devido à diversidade de marcas surgidas no mercado ultimamente, cada uma com suas características. Importante destacar que a maioria dos profissionais demonstrou saber quais são as soluções mais comumente usadas para realizar a limpeza, desinfecção ou esterilização; entretanto, para $20 \%(\mathrm{UR}=34)$ as dúvidas foram sobre qual tipo de solução e qual concentração deverá ser usada para cada tipo de material específico.

A desinfecção química deve ser a última opção para processamento de materiais termossensíveis devido à complexidade do processo, aos riscos oferecidos aos trabalhadores que manuseiam o produto e para o meio ambiente, quando desprezados em local inadequado ${ }^{13}$. Os germicidas usados para desinfecção de alto nível são os aldeídos (glutaraldeído, ortoformadeído, formaldeído), o ácido peracético, o peróxido de hidrogênio e a água eletrolisada; para desinfecção nos níveis intermediário e baixo, as soluções cloradas, álcool, quaternário de amônia, fenois e soluções iodadas ${ }^{13}$.

A concentração das soluções permanece a mesma recomendada pelo fabricante para imersão do material, o que varia é o tempo de exposição a ela para ocorrer a desinfecção de alto, médio ou baixo níveis. A RDC $8^{14}$ pró́be a esterilização por imersão em agentes químicos de instrumentais cirúrgicos e produtos para saúde considerados críticos. A Anvisa reforçou essa medida com a publicação da RDC $33^{15}$, em 2010, proibindo o registro de novos agentes saneantes na categoria de "esterilizantes" sob a forma líquida, estabelecendo prazo para adequação dos produtos esterilizantes e desinfetantes hospitalares para artigos semicríticos.

Na categoria "equipamentos e materiais", emergiram dúvidas sobre métodos de esterilização/desinfecção diretamente relacionadas à primeira categoria, na qual os profissionais perguntavam quais as soluções desinfetantes mais indicadas e como usá-las para a desinfecção dos 
materiais. Nessa categoria, a subcategoria "instrumentos" foi a segunda mais citada, com dúvidas em relação a todas as etapas do processo de preparo do material (limpeza, acondicionamento e esterilização) de instrumentais específicos, tais como: equipamentos de endoscopia, instrumentais cirúrgicos, nebulizadores, ambus, entre outros.

De acordo com a NR $15^{6}$, todos os produtos para a saúde passíveis de processamento devem passar obrigatoriamente pela limpeza por meio de ação mecânica (manual ou automatizada), atuando em superfícies internas (lúmen) e externas, de forma que tornem o produto seguro para manuseio e preparado para desinfecção ou esterilização. Após limpeza, os materiais devem passar pelos processos conforme sua classificação como produtos críticos, semicríticos ou não críticos. Alguns devem receber uma desinfecção simples, outros, uma desinfecção de alto nível, ou proceder a esterilização, dependendo do tipo de material de que são constituídos ${ }^{6}$.

Alguns profissionais relataram suas dúvidas em relação ao reprocessamento de materiais de uso único. Um estudo ${ }^{16}$ abordou a classificação dos produtos para saúde como de uso único ou reutilizáveis. Os primeiros deveriam ser utilizados uma única vez, porém, a prática de reúso desses materiais tem se tornado uma realidade, envolvendo uma série de questões - técnicas, econômicas, ambientais, éticas e jurídicas, visto que pode acarretar risco para a saúde dos usuários desses produtos. Os produtos reutilizáveis são considerados bens duráveis e requerem para o reprocessamento avaliação de desempenho, limpeza, desinfecção ou esterilização e controle de qualidade em todas as etapas para garantir sua reutilização.

Em 2006, a Anvisa publicou a Resolução no 2.605 com lista de produtos hospitalares proibidos de serem reutiliza$\operatorname{dos}^{17}$. No caso de surgir alguma dúvida, deve-se recorrer ao comitê de reprocessamentos de produtos da instituição, mas se este comitê não estiver implantado, quem decidirá é o responsável técnico pelo CME, que deve avaliar as condições do produto, os custos para o reprocessamento e, se após reprocessado, não irá apresentar risco para o usuário ${ }^{6}$.

Outra dúvida ainda em relação à categoria "equipamentos e materiais" foi sobre o tipo de embalagem mais segura para garantir a esterilidade do material por mais tempo. As funções primordiais da embalagem deveriam permitir a esterilização do material, mantendo sua esterilidade até o momento da utilização, e a retirada asséptica do material da embalagem, protegendo-os de possíveis eventos adversos ${ }^{13}$. É grande a variedade de produtos utilizados para embalar os materiais que irão ser esterilizados; portanto, para escolher qual será o invólucro mais adequado, é necessário levar em conta uma série de fatores, como custo benefício, condição financeira da instituição, geração de resíduos, treinamento da equipe de funcionários do CME, entre outros ${ }^{13}$. Deste modo, a embalagem confere ao material a proteção necessária para manutenção da esterilização, estando diretamente ligada às condições de manuseio, transporte $\mathrm{e}$ armazenamento, por isso, o material deve ser estocado em local seco, arejado, protegido de sujidade e grandes variações de temperatura - essas condições devem sempre ser monitoradas, assim como eventos que possam colocar a esterilização do material em risco ${ }^{18}$.

A dúvida menos expressiva foi em relação à formação de biofilme, quando por algum motivo a limpeza dos equipamentos não é eficiente ou quando as soluções empregadas não estão de acordo com a diluição. Estudo sobre remoção de biofilme, em aparelhos utilizados para endoscopia, apontou um alto risco de desenvolver o biofilme nesse tipo de equipamento, por serem complexos, não desmontáveis e nem transparentes, o que dificulta sua visualização interna e pode comprometer o processo de limpeza ${ }^{19}$; portanto, se a limpeza não for eficiente, o processo de desinfecção e/ou esterilização ficará todo comprometido.

Na categoria "legislação", a maioria das dúvidas foram em relação às "Normas / Portarias" e sobre as leis. No que diz respeito a esta categoria, pode-se citar a $\mathrm{RDC} 15^{6}$, documento fundamental para quem trabalha em CME, a qual dispõe sobre requisitos de boas práticas para o processamento de produtos para saúde e dá outras providências, visando à segurança do paciente e dos profissionais envolvidos ${ }^{6}$. Além desta, existem outras Resoluções, Notas Técnicas e Portarias, publicadas pela Anvisa, que complementam as recomendações para boas práticas no CME abordando aspectos não discutidos pela RDC 15.

Na categoria "validação do processo", a maioria das dúvidas direcionava-se ao tempo em que os materiais devem ser expostos em cada etapa de limpeza, desinfecção ou esterilização e quais os testes devem ser realizados para garantir uma esterilização efetiva no fim do processo. Sabe-se que usuários de saúde estão expostos a riscos inerentes a um processamento inadequado; quando o tempo for inadequado, o potencial de transmissão de microrganismos se mantém e a toxicidade causada por resíduos das soluções utilizadas poderá atingir o paciente ${ }^{19}$. 
Conforme indicação da RDC $15^{6}$, a cada carga de produtos esterilizados deve-se realizar o monitoramento com pacotes teste desafio com integradores químicos classe 5 ou 6. Quanto ao monitoramento com testes físicos, há necessidade de um registro para cada ciclo de esterilização ${ }^{6}$. O monitoramento com indicador biológico deve ser realizado diariamente, colocando o pacote desafio no ponto de maior dificuldade para ocorrer a esterilização na câmera interna da autoclave ${ }^{6}$. Os resultados desses testes devem ser armazenados na unidade e estar disponíveis para consulta sempre que solicitados ${ }^{6}$.

Observando as dúvidas enviadas à lista de discussão e avaliando as respostas emitidas, constatou-se que a maioria estava correta - aquelas que foram respondidas inadequadamente, imediatamente outro profissional apresentava a solução correta. As respostas sempre se fundamentavam em referência legal existente, com indicações de capítulos de normas e legislação disponíveis principalmente nos sites do Ministério da Saúde, da Anvisa, e no próprio site.

Embora diferentes categorias profissionais tenham manifestado suas dúvidas, constatou-se que estas eram semelhantes e direcionadas a garantir biossegurança aos usuários dos produtos para a saúde. As dúvidas existentes, se não esclarecidas, representariam risco para a qualidade do processamento dos produtos para a saúde e consequentemente da assistência à saúde.

\section{CONSIDERAÇÕES FINAIS}

Esta pesquisa permitiu conhecer as dúvidas sobre biossegurança relacionadas ao CME apresentadas por profissionais da área da saúde e suas respostas, condizentes com a realidade nacional existente. Constatou-se que as dúvidas mais frequentes estavam relacionadas às soluções, a equipamentos e materiais, à legislação e à validação de processo.

Evidenciou-se que o grupo de discussão do site pesquisado é uma ferramenta importante e disponível para auxiliar os profissionais da área da saúde a esclarecer suas dúvidas, contribuindo para uma assistência à saúde de qualidade. As dúvidas foram esclarecidas, em sua maioria, com base nas normas e leis existentes que norteiam o trabalho no CME.
Sobre as soluções, as principais dificuldades apontadas pelos participantes foram em relação aos nomes comerciais, às concentrações de diluição e à validade desta para realizar o processamento de materiais no CME. Em relação a equipamentos e materiais, as dúvidas foram quanto aos métodos de esterilização/desinfecção e à preocupação com marcação de instrumentais cirúrgicos de forma segura, garantindo uma vida útil ao material que não afete o processo de esterilização. Relativo à legislação, as principais dúvidas dos profissionais estavam relacionadas a quais Normas/Portarias ou Lei são indicadas para as atividades desenvolvidas no CME, a fim de garantir a assistência de qualidade. Na validação do processo, os profissionais expressaram suas dúvidas a respeito do tempo em que os materiais devem permanecer em cada etapa do processamento, para garantir uma limpeza efetiva, uma desinfecção segura e um processo de esterilização livre de falhas. Além dessa, também surgiu a preocupação quanto à realização de testes para garantir que os processos ocorreram livres de falhas garantindo a segurança do usuário.

Várias profissões ligadas à área da saúde manifestaram suas dúvidas e responderam aos questionamentos relacionadas ao CME, embora o maior número de profissionais envolvidos na discussão tenha sido de enfermeiros. Evidenciaram-se profissionais preocupados em prestar uma assistência de qualidade, procurando esclarecer suas dúvidas sempre baseados em alguma norma legal. Considera-se que o site pesquisado oferece uma gama de oportunidades para que os profissionais da área da saúde / gestores utilizem-no como fonte de consultas, servindo como educação continuada dos profissionais atuantes tanto na área especifica de CME quanto em qualquer área relacionada ao tema biossegurança dos serviços de saúde de todo o País. Infere-se a contribuição social desta pesquisa, servindo para divulgar a existência de um espaço onde os profissionais possam buscar apoio em suas dúvidas, sempre com respaldo legal.

Como limitações a este estudo cita-se a escassez de publicações nacionais na área da enfermagem que enfoque a biossegurança no CME nos últimos oito anos, sendo a maioria das publicações relacionadas anteriormente, embora as legislações tenham mudado principalmente nos últimos quatro anos. 


\section{REFERÊNCIAS}

1. Cararro TE, Gelbcke FL, Sebold LF, Kempfer SS, Zapelini MC, Waterkemper R. A biossegurança e segurança do paciente na visão de acadêmicos de enfermagem. Rev Gaúcha Enferm. 2012;33(3):14-9.

2. Bartolomei SRT, Lacerda RA. Trabalho do enfermeiro no Centro de Material e seu lugar no processo de cuidar pela enfermagem. Rev Esc Enferm USP. 2006;40(3):412-7.

3. Pereira MEC, Jurberg C, Soeiro MNC, Borba CM. A estruturação do Programa de Capacitação Profissional de Biossegurança no contexto do Projeto de Modernização da Gestão Científica do Instituto Oswaldo Cruz. Saúde Soc. 2010;19(2):440-8.

4. Ministério do Trabalho e Emprego (BR). Norma Regulamentadora $n^{\circ}$ 32. Portaria $n^{\circ} 485$, de 11 de novembro de 2005. Estabelece as diretrizes básicas para a implementação de medidas de proteção à segurança e à saúde dos trabalhadores dos serviços de saúde, bem como daqueles que exercem atividades de promoção e assistência à saúde em geral. Brasília, DF: MTE; 2005.

5. Santos MR, Ribeiro RP, Martins MB, Nascimento LA, Martins JT, Broff MCC. Avaliação da implantação da Norma Regulamentadora $32 \mathrm{em}$ um Hospital universitário. Cogitare Enferm. 2012 Jul-Set;17(3):524-30.

6. Agência Nacional de Vigilância Sanitária. Resolução n 15 , de 15 de março de 2012. Dispõe sobre requisitos de boas práticas para o processamento de produtos para saúde e dá outras providências. Brasília, DF: Anvisa; 2012.

7. Silva AC, Aguiar BGC. 0 enfermeiro na Central de Material e Esterilização: uma visão das unidades consumidoras. Rev Enferm UERJ. 2008 Jul-Set;16(3):377-81.

8. Brand $\mathrm{Cl}$, Fontana RT. Biossegurança na perspectiva da equipe de enfermagem de Unidades de Tratamento Intensivo. Rev Bras Enferm. 2014;67(1):78-84.

9. Martins VMF, Munari DB, Tipple AFV, Bezerra ALQ, Leite JL, Ribeiro LCM. Forças impulsoras e restritivas para trabalho em equipe em um Centro de Material e Esterilização de hospital escola. Rev Esc Enferm USP. 2011 Out;45(5):1179-86.
10. Gallas SR, Fontana RT. Biossegurança e a enfermagem nos cuidados clínicos: contribuições para a saúde do trabalhador. Rev Bras Enferm. 2010 Out;63(5):786-92.

11. Bardin L. Análise de conteúdo. São Paulo: Edições 70; 2011.

12. Schmidt DRC, Yonekura ONEKURA CSI, Gil RF. Instrumento para avaliação de detergentes enzimáticos. Rev Esc Enferm USP. 2008;42(2):282-9.

13. Graziano KU, Silva A, Psaltikidis EM. Enfermagem em centro de material e esterilização. Barueri: Manole; 2011. 417p.

14. Agência Nacional de Vigilância Sanitária. Resolução RCD 8, de 27 de fevereiro de 2009. Dispõe sobre as medidas para redução da ocorrência de infecções por Micobactérias de Crescimento Rápido em serviços de saúde. Brasília, DF: Anvisa; 2009.

15. Agência Nacional de Vigilância Sanitária. Resolução RCD nº 33 , de 16 de agosto de 2010 . Dispõe sobre a proibição de registro de novos produtos saneantes na categoria esterilizante para aplicação sob a forma de imersão, adequação dos produtos esterilizantes e desinfetantes hospitalares para artigos semicríticos já registrados na Anvisa e dá outras providências. Brasília, DF: Anvisa; 2010.

16. Costa EAM, Costa EA. Risco e segurança sanitária: análise do reprocessamento de produtos médicos em hospitais de Salvador, BA. Rev Saúde Pública. 2012;46(5):800-7.

17. Zilberstein B, Silva RCR, Valim SG, Yukui KTH, Valentim R. Reprocessamento de pinças de alta resolução para corte e coagulação. ABCD, Arq Bras Cir Dig. 2013;26(3):230-3.

18. Carvalho R. Enfermagem em centro de material, biossegurança e bioética. Barueri: Manole; 2015. 380p. (Manuais de especialização, 11).

19. Balsamo AC, Graziano KU, Schneider RP, Antunes Júnior M, Lacerda RA. Remoção de biofilme em canais de endoscópios: avaliação de métodos de desinfecção atualmente utilizados. Rev Esc Enferm USP. 2012;46(n. esp):91-8. 